\title{
Metal carbide/amorphous C-based nanocomposite coatings for tribological applications
}

J.C. Sánchez-López; Instituto de Ciencia de Materiales de Sevilla, Spain

D. Martínez-Martínez; Instituto de Ciencia de Materiales de Sevilla, Spain

M.D. Abad; Instituto de Ciencia de Materiales de Sevilla, Spain

A. Fernández; Instituto de Ciencia de Materiales de Sevilla, Spain

\begin{abstract}
This paper tries to assess the factors governing the tribological behaviour of different nanocomposites films composed by metallic carbides (MeC) mixed with amorphous carbon (a-C). Different series of MeC/a-C coatings (with Me: Ti(B) and W) were prepared by magnetron sputtering technique varying the power applied to the graphite target in order to tailor the carbon content into the films. A deep investigation of the chemical and structural features at the nano-scale is carried out by X-ray diffraction (XRD), X-ray photoelectron spectroscopy (XPS), electron energy-loss spectroscopy (EELS) and Raman spectroscopy techniques in order to establish correlations with the tribological properties measured by a pin-on-disk tribometer in ambient air. The analysis of the counterfaces by Raman confocal microscopy after the friction tests is used to follow the chemical phenomena occurring at the contact area responsible of the observed friction behaviour. The importance of determining the nanocrystalline/amorphous ratio is highlighted as a key-parameter to control the tribological properties. A comparative analysis of the mechanical and tribological performance of the three systems (TiC/a-C, WC/a-C, TiBC/a-C) is done and conclusions are obtained concerning the friction and wear mechanism involved.
\end{abstract}




\section{Introduction}

The increasing demands on the mechanical performance of hard coatings require the development of advanced new thin film materials with improved wear resistance in combination with low friction and high toughness. These requirements of multifunctionality could be met by developing alloyed, multilayer or nanocomposite coatings [1]. Isotropic nanocomposite coatings consisting of crystallites (typically based on hard phases as carbides or nitrides) encapsulated into an amorphous matrix provide considerable advances in terms of hardness, toughness, wear resistance and friction reduction [2-4]. The nature of the components, crystal size, and the amount of each phase determines the final properties of the material. According to Musil and Vleck [5], nanocomposites can be classified depending on the nature of the amorphous phase. If this second phase is hard, these nanocomposites show super- and ultra-hardness [6]. Some examples of these nanocomposites are $\mathrm{TiN} / \mathrm{Si}_{3} \mathrm{~N}_{4}[7,8], \mathrm{CrN} / \mathrm{SiN}_{\mathrm{x}}$ [9] and CrAlN/Si ${ }_{3} \mathrm{~N}_{4}$ [10]. The other kind of nanocomposites consists of those formed by crystals of a hard phase embedded in a soft phase. These soft phases usually have selflubricant properties and some examples from the literature are $\mathrm{ZrN} / \mathrm{Cu}[11,12]$, TiN/CN ${ }_{\mathrm{x}}$ [13], WC/DLC/WS 2 [14] and many other transition-metal carbides dispersed in amorphous carbon (a-C) matrix namely as MeC/a-C (TiC/a-C [15-19], WC/a-C [20, 21], TiBC/a-C [22,23]).

In this work, we present the preparation of $\mathrm{TiC} / \mathrm{a}-\mathrm{C}$, WC/a-C and TiBC/a-C nanocomposites by dual magnetron sputtering technique. This paper tries to assess the factors governing the tribological behaviour of different nanocomposites films by a combined microstructural and chemical analysis of the initial material and Raman analysis of the counterfaces after friction tests. The correlation between chemical features before and after friction modification allows to understand the tribological 
behaviour and to propose guidelines for tailored synthesis of such a kind of material. The samples will be labelled hereafter for simplicity as TiC/a-C, WC/a-C, and TiBC/aC although a mixture of different crystalline phases or variable stoichiometry can be present.

\section{Experimental details}

a) Film deposition

Three types of nanocomposites films were deposited by combining metallic carbide phases (TiC, WC and TiBC) with amorphous carbon (a-C) onto M2 steel substrates. The synthesis was carried out in a vacuum chamber at an initial pressure of $3 \times 10^{-4} \mathrm{~Pa}$ by co-sputtering of graphite and a second target ( $\mathrm{Ti}$, WC, or a composite ceramic (60:40) TiC: $\mathrm{TiB}_{2}$ ) in $0.60 \mathrm{~Pa}$ of argon. The proportion of nanocrystalline metal carbides (MeC) and amorphous carbon phases was obtained by controlling the ratio of sputtering power applied to the graphite target in respect to the second one, metal or metal carbide $\left(\mathrm{R}=\mathrm{P}_{\mathrm{C}} / \mathrm{P}_{\mathrm{Me}(\mathrm{C})}\right)$. The list of deposited films (1.5 to $2.0 \mu \mathrm{m}$ in thickness) and the chemical compositions are summarized in Table 1 . The substrates were mounted in a rotary sample-holder situated at $10 \mathrm{~cm}$ from the target. The temperature was found to vary in the range of $150-200{ }^{\circ} \mathrm{C}$ under the effect of the plasma as measured by a thermocouple. No additional heating or bias were applied to the substrates except for the TiBC/a-C system where a negative d.c. voltage of $100 \mathrm{~V}$ was used. Further details of particular synthesis conditions can be found elsewhere [24-26].

\section{b) Film characterization}

The crystal structure of the films was examined by X-ray diffraction analysis (XRD) at a low incidence angle of $1^{\circ}$ in order to increase the signal from the coating compared 
with the substrate. X-ray diffraction measurements were carried out using $\mathrm{Cu} \mathrm{K}_{\alpha}$ radiation $(1.54 \AA)$ in a Siemens D5000 diffractometer. Electron energy-loss spectroscopy (EELS) measurements were carried out with a Philips CM200 microscope operating at $200 \mathrm{kV}$ and equipped with a parallel detection EELS spectrometer from Gatan (766-2k). The core-loss edges were recorded with a 2-mm-entrance aperture yielding an energy resolution of $1.4 \mathrm{eV}$. The X-ray photoelectron spectroscopy (XPS) measurements were done in two equipments: a VG-Escalab 210 and a Leybold-Heraeus spectrometer operating both with non-monochromated $\mathrm{Mg} \mathrm{K}_{\alpha} \mathrm{X}$-ray source (1253.6 eV). Samples were previously cleaned using $\mathrm{Ar}^{+}$ion bombardment $\left(2.5 \times 10^{-3} \mathrm{~Pa} ; 2.5\right.$ $\mathrm{kV} ; 1.7 \mu \mathrm{A} / \mathrm{cm}^{2}$; 300s). These conditions were found as most appropriate to remove preferentially the hydrocarbon surface contamination layer without affecting the film elemental composition. Quantification was accomplished by determining the elemental peak areas, following a Shirley background subtraction and accounting for the relative sensitivities of the elements using Scofield cross-sections. Fitting analysis was then carried by a least squares routine using XPS Peak Fitting Programme 4.1 [27] on the C1s peak of the WC/a-C and TiBC/a-C films to estimate the relative amount of the different carbon bondings (carbides and amorphous carbon). Raman spectra measurements (200-2000 $\mathrm{cm}^{-1}$ ) were carried out with a LabRAM Horiba Jobin Yvon spectrometer equipped with a CCD detector and a He-Ne laser (532 nm) at $5 \mathrm{~mW}$. All the samples were analyzed during $100 \mathrm{~s}$ of exposure time and an aperture hole of 100 $\mu \mathrm{m}$. The tribological properties of the coatings were evaluated by ball-on-disk friction tests in unlubricated sliding against AISI52100 6-mm steel balls in ambient air at a relative humidity between $40-50 \%$. The test parameters were set to $5 \mathrm{~N}$ of applied load (maximum initial Hertzian contact pressure of $1.12 \mathrm{GPa}$ ), $10 \mathrm{~cm} / \mathrm{s}$ of linear speed, radius track between $6-10 \mathrm{~mm}$ and $1000 \mathrm{~m}$ of sliding distance. Normalized wear rates 
$\left(\mathrm{mm}^{3} / \mathrm{Nm}\right)$ were evaluated from cross-sectional profiles taken across the disk-wear track by means of stylus profilometry. Mechanical properties were evaluated by nanoindentation for the WC/a-C films with a Nanoindenter II (Nano Instruments, Inc., Knoxville, TN) using a diamond Berkovich (three-sided pyramid) and with a Fischercope H100 dynamic microprobe instrument using conventional Vickers indenter for the remaining two systems. The maximum load was selected in such a way that the maximum indentation depth did not exceed $10-15 \%$ of the coating thickness to avoid the influence of the substrate.

\section{Results and discussion}

Table 1 summarizes the chemical composition of the three prepared systems by EELS or XPS techniques. It is observed a continuous increment of the total carbon content as the relative sputtering power applied to the graphite target is varied from 0 to 4. It should be noticed that the values for the sputtering power ratio are not strictly comparable for the three systems since in the first case (TiC/a-C) carbon species can be originated exclusively by sputtering of the graphite target while in the other cases carbon can be sputtered from both targets.

Fig. 1 summarizes the friction coefficients $(\mu)$, wear rates $(k)$ and film hardness $(H)$ for the three series depending on the synthesis conditions. In all cases the friction coefficient exhibits a decrease to 0.1-0.2 by increasing the power applied to the graphite target. This friction drop is more important for the WC/a-C and TiBC/a-C whose initial friction values are higher, in the range of 0.6-0.8. The hardness values span between 827 GPa (TiC/a-C), 16-40 GPa (WC/a-C) and 22-30 GPa (TiBC/a-C). In general, the higher the power ratio the lower the hardness although this reduction is less marked in the latter case where the values remained almost constant. The variation of the wear 
rates of the films along a series appears to correlate with the friction coefficient rather than with the hardness values. Similar behaviour has been highlighted in other selflubricant hard nanocomposite coatings where the wear rate is not inversely proportional to the film hardness, as predicted by the Archard's law [28], but rather controlled by the properties of the lubricant phase $[18,29]$. Typical $k$ values are found in the range $10^{-6}$ $10^{-7} \mathrm{~mm}^{3} / \mathrm{Nm}$ although significant differences are noticed between the three systems. It should be mentioned that $\mathrm{k}$ values for samples (R0 and R0.1) of WC/a-C type are not provided due to the transfer of mating material (steel) to the surface making impossible the estimation of the wear track.

A better comparison of the tribological properties is shown in Fig. 2 for three selected coatings, one of each group, giving similar friction coefficient (0.2). An optical micrograph and a representative cross-sectional profile are also included as insets. As can be concluded by observation of the wear track the resistance increases in the sequence $\mathrm{TiBC}<\mathrm{TiC}<<\mathrm{WC}$. The results prove the lowest wear resistance of the TiBC system despite of its high hardness (31 GPa) and may be consequence of the brittleness properties of the $\mathrm{TiB}_{2}$ [30]. The remaining systems show reasonable wear resistance with $\left(1 \times 10^{-6} \mathrm{~mm}^{3} / \mathrm{Nm}\right.$; TiC/a-C) and $\left(<10^{-7} \mathrm{~mm}^{3} / \mathrm{Nm}\right.$; WC/a-C). Therefore, it can be concluded that both mechanical and tribological properties appear controlled by the composition of the coatings, determined by the relative sputtering power applied to the graphite target. It is therefore worth determining the crystalline composition of the samples and the distribution of carbon atoms into carbide and a-C forms.

The crystalline fraction was analyzed by means of XRD and electron diffraction techniques [24-26]. Fig. 3 shows XRD patterns for representative samples for the three systems. In the TiC/a-C coatings the diffraction peaks from $\mathrm{TiC}$ phase were identified together with some peaks originated by a titanium underlayer and Fe from the 
substrates. The coatings exhibit a (111) preferred orientation as the degree of crystallinity increases. From the broadening of the TiC (220) peak and the Scherrer formula, average crystallite sizes were determined to vary between 2 and $30 \mathrm{~nm}$ (see Table 1). Fig. 3b shows the change in the XRD patterns of the WC/a-C films with the applied sputtering power ratio. The R0 film, grown by sputtering from the single WC target, crystallizes in the hexagonal $\alpha-\mathrm{W}_{2} \mathrm{C}$ phase with a marked $(002 / 101)$ orientation. From the broadening of (100) and (002/101) reflection peaks an average crystallize size of $9 \mathrm{~nm}$ was estimated using the Scherrer formula. The XRD pattern of R0.1 film exhibits an additional small peak situated around $42^{\circ}$ attributed to the (200) reflection peak of the cubic $\beta$-WC 1 -x phase. These results suggest that the $\mathrm{R} 0.1$ film is a biphase system containing $\mathrm{W}_{2} \mathrm{C}$ and $\beta-\mathrm{WC}_{1-\mathrm{x}}$. The crystallite size in $\mathrm{W}_{2} \mathrm{C}$ was reduced to about $7 \mathrm{~nm}$ while in $\beta-\mathrm{WC}_{1-\mathrm{x}}$ the crystallite size is estimated to be about $5 \mathrm{~nm}$. In contrast, for higher sputtering power ratio values, the diffraction patterns of the associated films exhibit mainly a broad peak located at $\approx 38^{\circ}$ which can be associated with the (111) reflection peak of the fcc $\beta$ - $\mathrm{WC}_{1-\mathrm{x}}$ phase, a rough estimation gives a crystallite size of 2$3 \mathrm{~nm}$. The diffractograms shown for TiBC/a-C coatings (Fig. 3c) did not reveal welldefined diffraction patterns except the peak at $44^{\circ}$ originated by the steel substrate and a very broad band at $35^{\circ}$ whose intensity increases with the carbon content. By comparing the diffractrograms with the XRD database this peak can be originated by (100) $\mathrm{TiB}_{2}$ or (111) TiC planes although the proximity in their main diffraction peaks together with the nanocrystalline or quasi-amorphous character does not allow to discriminate between them. In addition, this broad peak at $35^{\circ}$ can be also attributed to a ternary phase including titanium, carbon and boron $\left(\mathrm{TiB}_{\mathrm{x}} \mathrm{C}_{\mathrm{y}}\right)$ from the introduction of carbon atoms inside the hexagonal $\mathrm{TiB}_{2}$ lattice [31]. It is noticed from the analysis of XRD 
patterns a slight increase of the crystallinity at higher $\mathrm{C}$ concentration what can be interpreted by the formation of a ternary $\mathrm{TiB}_{\mathrm{x}} \mathrm{C}_{\mathrm{y}}$ phase [26].

In order to estimate the relative amount of a-C in respect to the total carbon content (i.e. lubricant fraction $x_{a-C}$ ) EELS and XPS have been used. Both characterization techniques are sensitive to the local coordination about the excited atom (i.e. carbon in this case), being appropriate to evaluate the fraction of carbon atoms in each phase (a-C or $\mathrm{MeC}$ ). In Fig. 4a, the C K-edge EEL spectra of TiC/a-C of samples are plotted together with two references of $\mathrm{TiC}$ and a-C films respectively. The main features observed in the fine structure are the two peaks centred at $\approx 285$ and $\approx 295 \mathrm{eV}$, named $\pi$ and $\sigma$ transitions respectively, although varying the relative shape and energy position. Thus, a gradual transition is denoted when going from $\mathrm{TiC}$ to a-C spectrum indicative of a progressive enrichment of the amorphous phase in the film composition. By linear combination of these two standards the amount of the a-C phase was estimated ranging from 5 to $85 \%$ for the TiC/a-C nanocomposite coatings under study. Fig. 4d displays the fitted curve and the experimental data obtained for sample R2B as example giving 59\% of a-C. This estimation is in good agreement with the percentage of free carbon calculated from the atomic chemical composition assuming a 1:1 stoichiometry for TiC [24]. The estimation of the phase composition by EELS in the case of TiBC and WC results very complicated due to the existence of various crystalline forms, nonstoichiometric, and the absence of reference data in the literature. For these reasons, XPS fitting of C1s peak was assessed in these cases.

Fig. $4 \mathrm{~b}$ and $4 \mathrm{c}$ displays the C1s XPS peak for the WC/a-C and TiBC/a-C nanocomposite films respectively. The values for FWHM were set at 1.5 (carbides), 1.7-1.8 (a-C) and 2.0-2.2 (C-O) and the Gaussian-to-lorentzian peak shape (0.8 to 1.0). For the WC/a-C films, a variation in the relative intensity between these two types of $\mathrm{C}$ 
bonds is clearly noticed along the series. The C1s peak was fitted assuming main contributions from W-C (283.5 eV) and a-C (285.0 eV) (see Fig. 4e) [32]. The a-C content starts to be significant from R0.5 (15.7\%) when the total C content overpasses the 50 at. \%. From R1 the shoulder due to the a-C atoms becomes more visible and comparable to the carbide component. In the case of the TiBC (see Fig. 4f), the C peak can be deconvoluted into three principal components at 282.2, 283.2 and $284.5 \mathrm{eV}$ $[33,34]$. The peak structure was similar for all the coatings varying the relative intensities among the three main peaks. The binding energy for a pure TiC phase is around $282.0 \mathrm{eV}$ and that of amorphous carbon phase is located at $\approx 284.5 \mathrm{eV}$. The predominant peak at $283.2 \mathrm{eV}$ can be due to the incorporation of carbon atoms to the $\mathrm{TiB}_{2}$ phase forming the $\mathrm{TiB}_{\mathrm{x}} \mathrm{C}_{\mathrm{y}}$ phase whose peak is shifted towards higher energies due to the different electronegativity between $\mathrm{C}$ and $\mathrm{B}$ as reported previously by other authors $[33,34]$. The $x_{a-C}$ fraction remains steady about $20 \%$ for the three first samples of the series and then increases continuously up to approximately $50 \%$. It seems that when no more $C$ can be accommodated into the $\mathrm{TiB}_{\mathrm{x}} \mathrm{C}_{\mathrm{y}}$ phase, this excess appears as free carbon phase. A similar trend was observed by Gilmore et al. with $\mathrm{TiB}_{2} / \mathrm{DLC}$ coatings [22].

Once the fraction of carbon atoms present in the amorphous phase has been evaluated for each coating it is possible to revise the friction properties as a function of this key-parameter. Fig. 5 plots the evolution of friction coefficients vs. lubricant fraction, $x_{a-C}$. In an analogous way to Fig. 1 the friction tends to decrease rapidly for the WC/a-C and TiBC/a-C systems from $0.6-0.8$ to values below 0.2 for $x_{a-C}$ contents above 40\%. For obtaining a similar low friction coefficient with the TiC/a-C nanocomposite films it is necessary the a-C fraction rises up to $60 \%$. Further reduction of the friction, even below 0.1, can be achieved by increasing the fraction lubrication to a higher extent 
but always smaller percentages are needed for the WC/a-C and TiBC/a-C films. For instance, $\mu \sim 0.1$ is attained with a $x_{a-C}$ of $75 \%$ for the TiC/a-C series but only $49 \%$ is necessary in the case of TiBC/a-C nanocomposites. The reasons behind this different tribological behaviour are not clear but in order to have a better insight about the chemical phenomena occurring at the contact area analysis of the ball counterfaces by Raman confocal microscopy was tempted. For that purpose we have selected two coatings of each nanocomposite family representative of the high and low friction regime $(\mu<0.2)$. This corresponds in terms of a-C contents samples displaying $x_{a-c} \leq$ $20 \%$ or $x_{a-c} \geq 30-40 \%$ respectively.

Fig. 6 shows the spectra taken from transferred material on the ball scar together with the initial films for comparison purposes. The left column (Fig. 6a, 6c and 6e) displays the results obtained for low $x_{a-C}$ values $(<20 \%)$. The main features that appear after friction correspond to the formation of metal oxides and the incipient development of the $\mathrm{D}$ and $\mathrm{G}$ peaks. In the case of the TiC/a-C $\left[5 \% x_{a-C}\right]$ films the initial peaks (284, 384, 582 and $675 \mathrm{~cm}^{-1}$ ) attributed to disordered TiC phase disappear and transform to titanium oxide and/or iron titanate $\left(\mathrm{FeTiO}_{3}\right)$ at approximately 430 and $600 \mathrm{~cm}^{-1}$, originated by partial oxidation of the $\mathrm{TiC}$ phase [35]. Fig. 6c displays the results obtained for the WC/a-C [8\% $\left.x_{a-C}\right]$ sample. The new bands at frequencies of 360, 720 and $960 \mathrm{~cm}^{-1}$ can be assigned to a mixture of iron and tungsten oxides. This latter peak is usually assigned in the literature to the stretching mode of $\mathrm{W}=\mathrm{O}$ double bonds that appear on the boundaries of amorphous or nanostructured tungsten oxides [36]. These results correlate with the strong interaction of the steel counterpart with the film surface for samples R0 and R0.1 whose wear rate was not possible to be measured. In the last case, the TiBC/a-C $\left[20 \% x_{a-C}\right]$ sample (Fig. 6e) shows a broad and intense band at 710 $\mathrm{cm}^{-1}$ owing to iron oxide (maghemite) produced by oxidation of the steel ball compared 
to the $\mathrm{D}\left(1375 \mathrm{~cm}^{-1}\right)$ and $\mathrm{G}\left(1580 \mathrm{~cm}^{-1}\right)$ peaks. It is therefore inferred that when the amount of lubricant phase is scarce the high friction promotes the reaction with the steel ball and film oxidation although it must be noticed that for the TiC/a-C the reaction with the iron was not so manifested. This could justify the lower friction values obtained for this system despite its low a-C content. Similar trend has also been noticed in a literature survey for many different TiC/a-C(H) coatings prepared by PVD and PACVD methods [18].

The analysis of the second group of representative samples (Fig. 6b, 6d and 6f ), those yielding to low friction, shows similar features. In all cases, the D and G peaks on the ball counterfaces appear better defined as compared to the initial film spectra and the results obtained with its partner sample with lower a-C content. This enhancement is especially remarkable in the case of WC/a-C $\left[43 \% x_{a-C}\right]$ (Fig. 6d) and TiBC/a-C [30\% $x_{a-C}$ graphs (Fig. 6f) where these bands were initially very weak. The formation of metallic oxides is much reduced in these cases and only a small peak due to $\mathrm{W}=\mathrm{O}$ at $945 \mathrm{~cm}^{-1}$ (cf. Fig. 6d) is detected. In the first case (TiC/a-C) the spectra looks like almost identical, with a pronounced D and G peaks, although the G-peak intensity and position increase a little. Moreover, for the three types of nanocomposite films, the Gpeaks position shifts towards higher frequencies $\left(\sim 1580\right.$ to $\left.1600 \mathrm{~cm}^{-1}\right)$. These changes are correlated with a reduction of defects and clustering of an initial highly disordered $\mathrm{sp}^{2}$-bonded C network [37]. This conclusion appears coincident with the tribological behaviour in air of DLC and other carbon-based coatings [18,25,38,39].

The comparison of the Raman spectra for the initial films (Fig. 6b, 6d and 6f) enables to show the higher relative concentration of disordered $\mathrm{sp}^{2}$ carbon material in the TiC/aC system, in agreement with the estimation of the atomic fraction of a-C obtained by EELS and XPS. However, the formation of a graphitic-like material in the contact 
matches always with the decrease of friction. A possible explanation to this tribological behaviour can be given by considering a friction induced decomposition of the nonstoichiometric carbides and/or metastable solid solutions releasing free carbon and forming structures that accomodate carbon vacancies. In this sense, the decomposition of tungsten carbide generating carbon and substoichiometric $\mathrm{W}_{\mathrm{x}} \mathrm{C}_{\mathrm{y}}$ compounds is described in the phase diagram of the $\mathrm{W}-\mathrm{C}$ system and was confirmed during thermal annealing of these same coatings [40,41]. In the case of the TiBC/a-C, previous studies have pointed out the formation of a metastable hexagonal $\mathrm{TiB}_{\mathrm{x}} \mathrm{C}_{\mathrm{y}}$ phase by addition of carbon into a initial hexagonal $\mathrm{TiB}_{2}$ structure [31,42] or binary and ternary solid solution of the Ti-B-C system $[42,43]$. The increase of temperature and friction forces generated in the contact during friction test may contribute to $\mathrm{C}$ removal although further studies are necessary to confirm this hypothesis. Therefore, the low friction conditions during the friction tests can be ascribed to the in situ supply of disordered free carbon that lubricates the contact similarly to other carbon-based compounds.

\section{Conclusions}

The tribological behaviour of nanocomposites films composed by metallic carbides mixed with amorphous carbon (a-C) was assessed by comparing TiC/a-C, WC/a-C and TiBC/a-C series prepared by magnetron sputtering technique with variable carbon contents. The friction coefficients, wear rates and hardness values appear to correlate with the overall carbon content. By estimation of the percentage of carbon atoms situated in the amorphous lubricant phase a comparative analysis was done in selected samples providing similar friction coefficient $(\sim 0.2)$. The Raman analysis of the ball counterfaces demonstrates the formation of a graphitic-like material for the more lubricant films (i.e. those containing higher fraction of a-C) during friction. The relative 
amount of a-C $\left[x_{a-C}\right]$ needed to reduce friction below 0.2 is diminished in the nanocomposite films formed by metastable or non-stoichiometric carbides (TiBC/a-C and WC/a-C) from 55-60 to 30-40\%. This decrease was attributed to a partial C release into the contact due to the decomposition or transformation of these compounds under friction. Nevertheless, the wear rate is worse for the TiBC/a-C due to its brittle character. A good compromise between mechanical and tribological properties is then found for the WC/a-C system with hardness around $15-20 \mathrm{GPa} ; \mu \sim 0.2$; wear rates $10^{-7}$ $10^{-8} \mathrm{~mm}^{3} / \mathrm{Nm}$ for $\left[x_{a-C}\right]$ values of $40-45 \%$. This value would guarantee the generation of sufficient lubricant amorphous carbon phase in the contact region without a great decrease of the hardness values (above $15 \mathrm{GPa}$ ) and wear resistance.

\section{Acknowledgements}

The Spanish Ministery of Science and Innovation (projects $\mathrm{n}^{\mathrm{o}}$ MAT2004-01052, MAT2007-66881-C02-01 and CONSOLIDER CSD2008-00023) and European Union (NOE EXCELL NMP3-CT-2005-515703) are acknowledged for financial support. 


\section{References}

[1] R. Hauert, J. Pastcheider, Adv. Eng. Mater. 2 (2000) 47.

[2] A.A. Voevodin, S.V. Prasad, J.S. Zabinski, J. Appl. Phys. 82 (1997) 855.

[3] A.A. Voevodin, J.S. Zabinski, J. Mater. Sci. 33 (1998) 319.

[4] A.A. Voevodin, T.A. Fitz, J.J. Hu, J.S. Zabinski, J. Vac. Sci. Technol. A 20 (2002) 1434.

[5] J. Musil, J. Vleck, Surf. Coat. Technol. 142 (2001) 557.

[6] S. Veprek, S. Reiprich, Thin Solid Films 265 (1995) 64.

[7] P. Nesladek, S. Veprek, Phys. Status Solidi A 177 (2000) 53.

[8] L. Rebouta, C.J. Tavares, R. Aimo, Z. Wang, K. Pischow, E. Albes, T.C. Rojas, J. Odriozola, Surf. Coat. Technol. 133-134 (2000) 234.

[9] E. Martinez, R. Sanjines, A. Karimi, J. Esteve, F. Levy, Surf. Coat. Technol. 180181 (2004) 570.

[10] I.W. Park, D.S. Kang, J.J. Moore, S.C. Kwon, J.J. Rha, K.H. Kim, Surf. Coat. Technol 201 (2007) 5223.

[11] S. Lang, T. Beck, A. Schattke, C. Uhlaq, A. Dinia, Surf. Coat. Technol. 181-181 (2004) 85.

[12] J. Musil, P. Zeman, Vacuum 52 (1999) 269.

[13] D. Li, X.W. Lin. S.C, Cheng, V.P. Dravid, Y. Chung, M. Wong, W.D. Sproul, Appl. Phys. Lett 68 (1996) 1211.

[14] A.A. Voevodin , J.P. O’Neill, J.S. Zabinski, Surf. Coat. Technol. 119 (1999) 36.

[15] S. Zhang, X.L. Bui, J. Jiang, X.M. Li, Surf. Coat. Technol. 198 (2005) 206

[16] W. Gulbinski, S. Mathur, H. Shen, T. Suszko, A. Gilewicz, B. Warcholinski, Appl. Surf. Sci. 239 (2005) 302.

[17] M. Stuber, H. Leiste, S. Ulrich, H. Holleck, D. Schild, Surf. Coat. Technol. 150 (2002)218.

[18] J.C. Sanchez-Lopez, D. Martinez-Martinez, C. Lopez-Cartes, A. Fernandez, Surf. Coat. Technol. 202 (2008) 4011.

[19] D. Martinez-Martinez, C. Lopez-Cartes, A. Fernandez, J.C. Sanchez-Lopez, Surf. Coat. Technol. 203 (2008) 756. 
[20] S.J. Park, K.R. Lee, D.H. Ko, K.Y. Eun, Diamond Relat. Mater, 11 (2002) 1747.

[21] J.P. Palmsquist. Z.S. Czigany, M. Oden, J. Neidhart, L. Hutman, U. Jansson, Thin Solid Films 444 (2003) 29.

[22] R. Gilmore, M. A. Baker, P.N. Gibson, W. Gissler, Surf. Coat. Technol. 105 (1998) 45.

[23] D. Zhong, E. Sutter, J.J. Moore, G.G.W. Mustoe, E.A. Levashov, J. Disam, Thin Solid Films 398-399 (2001) 320.

[24] D. Martinez-Martinez, C. Lopez-Cartes, A. Fernandez, J.C. Sanchez-Lopez. Thin Solid Films 517 (2009) 1662.

[25] M.D. Abad, J.C. Sanchez-Lopez, N. Cusnir, R. Sanjines, J. Appl. Phys. 105 (2009) 033510 .

[26] M.D. Abad, D. Caceres, Y.S. Pogozhev, D.V. Shtansky, J.C. Sanchez-Lopez, Plasma Process Polym. (in press), DOI: 10.1002/ppap.200930403.

[27] http://www.phy.cuhk.edu.hk/ surface/XPSPEAK/

[28] J.F. Archard, J. Appl. Phys. 24 (1953) 981.

[29] D. Martinez-Martinez, C. Lopez-Cartes, A. Justo, A. Fernandez, J.C. SanchezLopez, A. Garcia-Luis, M. Brizuela, J. I. Oñate, J. Vac. Sci. Technol. A 23 (2005) 1732.

[30] R. Wiedemann, V. Weihnacht, H. Oettel, Surf. Coat. Technol. 116-119 (1999) 302.

[31] O. Knotek, R. Breidenbach, F. Jungblut and F. Löffler, Surf. Coat. Technol. 43-44 (1990) 107.

[32] A. Czyzniewski, Thin Solid Films 433 (2003) 180.

[33] M.A. Baker, Surf. Coat. Technol. 201 (2007) 6105.

[34] I.-W. Park, K.H. Kim, A.O. Kunrath, D. Zhong, J.J. Moore, A.A. Voevodin, E.A. Levashov, J. Vac. Sci. Technol. 23 (2005) 588.

[35] M. Gotic, M. Ivanda, S. Popovic, S. Music, A. Sekulic, A. Turkovic, K. Furic, J. Raman Spectroscopy 28 (1997) 555.

[36] A. Baserga, V. Russo, F. Di Fonzo, A. Bailini, D. Cattaneo, C.S. Casari, A.Li. Bassi, C.E. Bottani, Thin Solid Films 515 (2007) 6465.

[37] J. C. Sanchez-Lopez, A. Erdemir, C. Donnet, T.C. Rojas, Surf. Coat. Technol. 163164 (2003) 444. 
[38] A. Erdemir, C. Donnet (Eds.), Fundamentals and Applications, Springer, New York, 2008.

[39] J.C. Sanchez-Lopez, D. Martinez-Martinez, C. Lopez-Cartes, C. Fernandez-Ramos, A. Fernández, Surf. Coat. Technol. 200 (2005) 40.

[40] B. Trindade, M.T. Vieira, E. Bauer-Grosse, Acta Mater. 46 (1998) 1731.

[41] S. El Mrabet, M.D. Abad, C. Lopez-Cartes, D. Martinez-Martinez, J.C. SanchezLopez, Plasma Process Polym. (in press), DOI: 10.1002/ppap.200931004.

[42] H. Holleck, M. Lahres, Mat. Sci. Eng. 140 (1991) 609.

[43] V. Gorokhovsky, C. Bowman, P. Gannon, D. Van Vorous, A.A. Voevodin, A. Rutkowski, C. Muratore, R.J. Smith, A. Kayani, D. Gelles, V. Shutthadanandan, B.G. Trusov, Surf. Coat. Technol. 201 (2006) 3732. 


\section{Table and Figure captions}

Table 1. Chemical composition, crystal size, relative amount of a-C in respect to the total $\mathrm{C}$ content $\left(x_{\mathrm{a}-\mathrm{C}}\right)$ and tribo-mechanical properties as a function of coating series.

Figure 1. Tribological and mechanical properties as a function of the synthesis conditions for the different TiC/a-C (a), WC/a-C (b) and TiBC/a-C (c) coatings.

Figure 2. Friction coefficient vs. sliding distance, optical micrograph and crosssectional profile of the wear track obtained for coatings R2B-TiC/a-C (a), R2-WC/a-C (b), R1-TiBC/a-C (c).

Figure 3. Grazing angle XRD diffractograms of selected coatings from the series TiC/a-C, WC/a-C and TiBC/a-C deposited onto stainless steel substrates. JCPDS cards numbers of identified phases: 20-1316 (WC 1 -x), 35-0776 ( $\left.\mathrm{W}_{2} \mathrm{C}\right), 32-1383$ (TiC), 075-0967 ( $\left.\mathrm{TiB}_{2}\right), 01-1197$ (Ti), 01-1262 (Fe). Ti ( ${ }^{\circ}$ ) peaks are originated by a $\mathrm{Ti}$ underlayer deposited in the TiC/a-C system for improving the adhesion. Fe $(\diamond)$ peaks come from M2 steel substrates.

Figure 4. Carbon K-edge EELS spectra of TiC/a-C coatings (a) and XPS spectra in the C1s region for the coatings WC/a-C (b) and TiBC/a-C (c). Curve fitted EELS C K-edge spectra for the R2B-TiC/a-C coating (d). Curve fitted XPS $\mathrm{C}$ 1s peak for the R1-WC/a-C (e) and R1-TiBC/a-C (f) coatings.

Figure 5. Friction coefficients as a function of the fraction of a-C in respect to the total carbon content $\left(x_{a-c}\right)$.

Figure 6. Raman spectra obtained from the ball scar after tribo-testing in comparison with the initial film spectra for coatings TiC/a-C [5\% $\left.x_{a-C}\right]$ (a), TiC/a-C [59\% $\left.x_{a-C}\right](b)$, WC/a-C $\left[8 \% x_{a-C}\right](\mathrm{c}), \mathrm{WC} / \mathrm{a}-\mathrm{C}\left[43 \% x_{a-C}\right](\mathrm{d}), \mathrm{TiBC} / \mathrm{a}-\mathrm{C}\left[20 \% x_{a-C}\right]$ (e) and TiBC/a-C $\left[30 \% x_{a-C}\right](f)$. 
Table 1

\begin{tabular}{|c|c|c|c|c|c|c|c|c|c|}
\hline \multicolumn{2}{|c|}{ Coating } & \multirow{2}{*}{$\mathrm{R}$} & \multicolumn{2}{|c|}{$\begin{array}{l}\text { Chemical composition } \\
\text { (at. \%) }\end{array}$} & \multirow{2}{*}{$\begin{array}{l}\text { Crystal size } \\
\quad(\mathrm{nm})\end{array}$} & \multirow{2}{*}{$\begin{array}{l}X_{\mathrm{a}-\mathrm{c}} \\
(\%)\end{array}$} & \multicolumn{3}{|c|}{ Tribo-mechanical properties } \\
\hline Series & Sample & & $\mathrm{Ti}$ & $\mathrm{C}$ & & & & $\left(\mathrm{mm}^{3} \mathrm{~N}^{-1} \mathrm{~m}^{-1}\right)$ & $\begin{array}{c}\mathrm{H} \\
(\mathrm{GPa})\end{array}$ \\
\hline \multirow[t]{5}{*}{ TiC/a-C } & R1 & 1 & 56.4 & 43.6 & $\approx 30$ & 5 & 0.31 & $4.75 \times 10^{-6}$ & 22.3 \\
\hline & $\mathrm{R} 2$ & 2 & 34.4 & 65.6 & $6-7$ & 53 & 0.25 & $2.56 \times 10^{-6}$ & 27.0 \\
\hline & $\mathrm{R} 2 \mathrm{~B}$ & 2 & 29.3 & 70.7 & $6-7$ & 59 & 0.20 & $1.22 \times 10^{-6}$ & 14.1 \\
\hline & R3 & 3 & 20.6 & 79.4 & $2-3$ & 75 & 0.09 & $2.60 \times 10^{-7}$ & 7.1 \\
\hline & R4 & 4 & 14.5 & 85.5 & $2-3$ & 85 & 0.13 & $1.00 \times 10^{-7}$ & 8.0 \\
\hline
\end{tabular}

\begin{tabular}{|c|c|c|c|c|c|c|c|c|c|}
\hline \multicolumn{2}{|c|}{ Coating } & \multirow{2}{*}{$\mathrm{R}$} & \multicolumn{2}{|c|}{$\begin{array}{l}\text { Chemical composition } \\
\text { (at. \%) }\end{array}$} & \multirow{2}{*}{$\begin{array}{c}\text { Crystal size } \\
(\mathrm{nm})\end{array}$} & \multirow{2}{*}{$\begin{array}{l}X_{\mathrm{a}-\mathrm{C}} \\
(\%)\end{array}$} & \multicolumn{3}{|c|}{ Tribo-mechanical properties } \\
\hline Series & Sample & & W & C & & & $\mu$ & $\begin{array}{c}\mathrm{k} \\
\left(\mathrm{mm}^{3} \mathrm{~N}^{-1} \mathrm{~m}^{-1}\right)\end{array}$ & $\begin{array}{c}\mathrm{H} \\
(\mathrm{GPa}) \\
\end{array}$ \\
\hline \multirow{7}{*}{ WC/a-C } & R0 & 0 & 66.1 & 33.9 & $\approx 9$ & 21 & 0.84 & -- & 35.7 \\
\hline & R0.1 & 0.1 & 60.9 & 39.1 & 5-7 & 8 & 0.81 & --- & 39.6 \\
\hline & R0.3 & 0.3 & 49.1 & 50.9 & $2-3$ & 20 & 0.59 & $9.9 \times 10^{-6}$ & 23.2 \\
\hline & R0.5 & 0.5 & 41.8 & 58.2 & $2-3$ & 29 & 0.51 & $3.2 \times 10^{-6}$ & 22.4 \\
\hline & $\mathrm{R} 1$ & 1 & 33.3 & 66.7 & -- & 40 & 0.36 & $7.2 \times 10^{-7}$ & 20.7 \\
\hline & $\mathrm{R} 2$ & 2 & 28.5 & 71.5 & --- & 43 & 0.20 & $7.2 \times 10^{-8}$ & 19.5 \\
\hline & R3 & 3 & 27.5 & 72.5 & --- & 45 & 0.19 & $4.4 \times 10^{-8}$ & 15.8 \\
\hline
\end{tabular}

\begin{tabular}{|c|c|c|c|c|c|c|c|c|c|c|}
\hline \multicolumn{2}{|c|}{ Coating } & \multirow{2}{*}{$\mathrm{R}$} & \multicolumn{3}{|c|}{$\begin{array}{c}\text { Chemical composition } \\
\text { (at. \%) }\end{array}$} & \multirow{2}{*}{$\begin{array}{c}\text { Crystal size } \\
(\mathrm{nm})\end{array}$} & \multirow{2}{*}{$\begin{array}{l}X_{a-C} \\
(\%)\end{array}$} & \multicolumn{3}{|c|}{ Tribo-mechanical properties } \\
\hline Series & Sample & & & B & C & & & $\mu$ & $\frac{\mathrm{k}}{\left(\mathrm{mm}^{3} \mathrm{~N}^{-1} \mathrm{~m}^{-1}\right)}$ & $\begin{array}{c}\mathrm{H} \\
(\mathrm{GPa})\end{array}$ \\
\hline \multirow[t]{6}{*}{ TiBC/a-C } & R0 & 0 & 45.0 & 23.8 & 31.2 & --- & 20 & 0.63 & $1.2 \times 10^{-5}$ & 23.8 \\
\hline & $\mathrm{R} 0.2$ & 0.2 & 46.9 & 16.7 & 36.4 & --- & 19 & 0.62 & $1.3 \times 10^{-5}$ & 28.1 \\
\hline & R0.5 & 0.5 & 43.6 & 17.2 & 39.3 & --- & 23 & 0.43 & $1.8 \times 10^{-5}$ & 26.0 \\
\hline & $\mathrm{R} 1$ & 1 & 38.8 & 12.0 & 49.2 & $\approx 2$ & 30 & 0.23 & $4.3 \times 10^{-6}$ & 30.7 \\
\hline & $\mathrm{R} 2$ & 2 & 24.6 & 14.4 & 61.0 & $2-3$ & 41 & 0.22 & $2.3 \times 10^{-6}$ & 22.2 \\
\hline & R3 & 3 & 16.4 & 12.3 & 71.3 & $2-3$ & 49 & 0.11 & $8.7 \times 10^{-7}$ & 24.6 \\
\hline
\end{tabular}




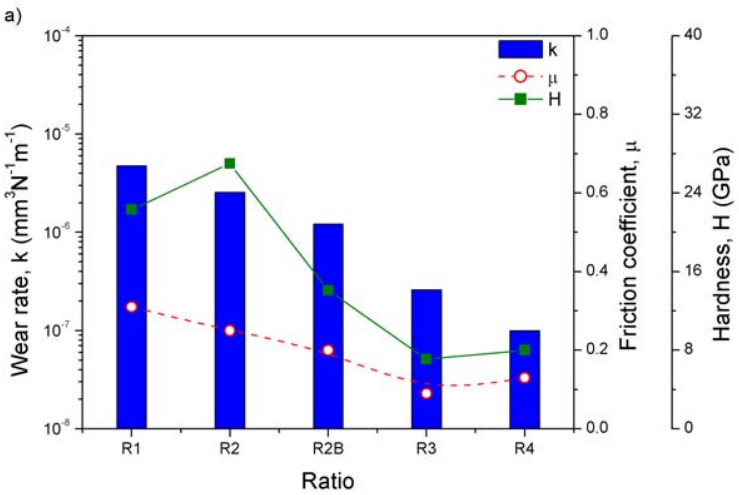




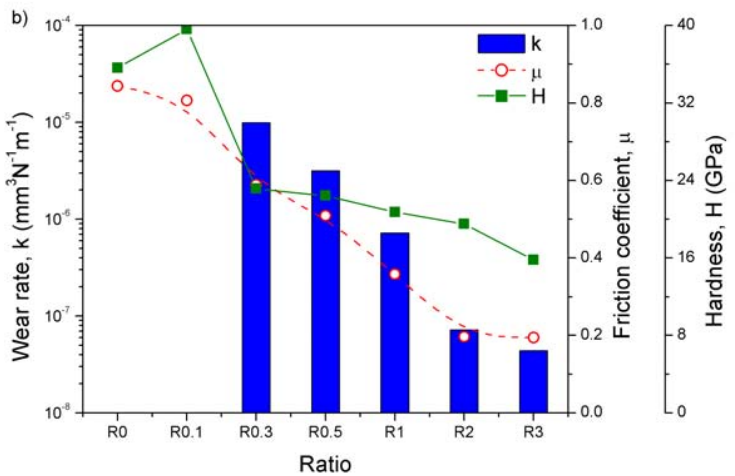




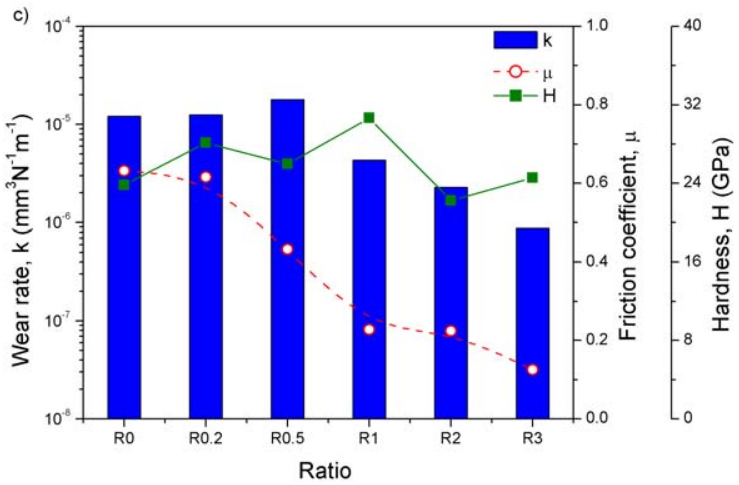


a)

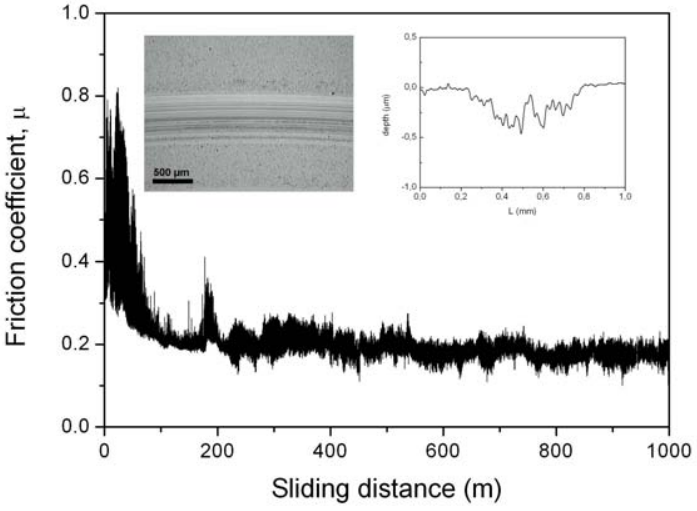




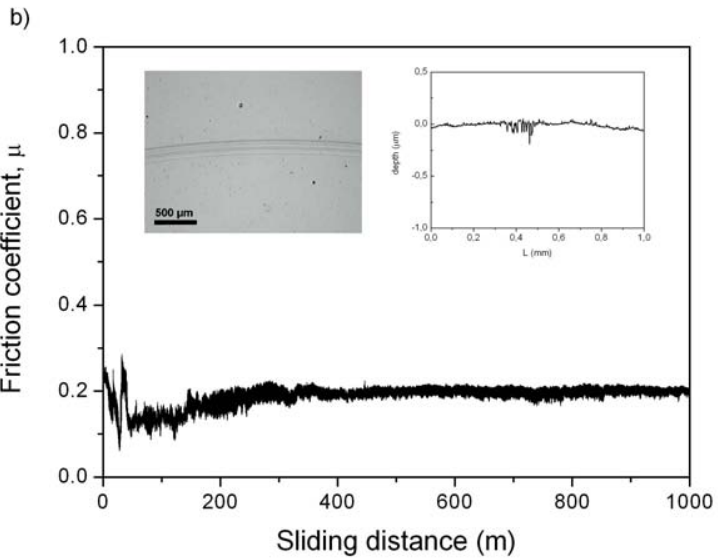


c)

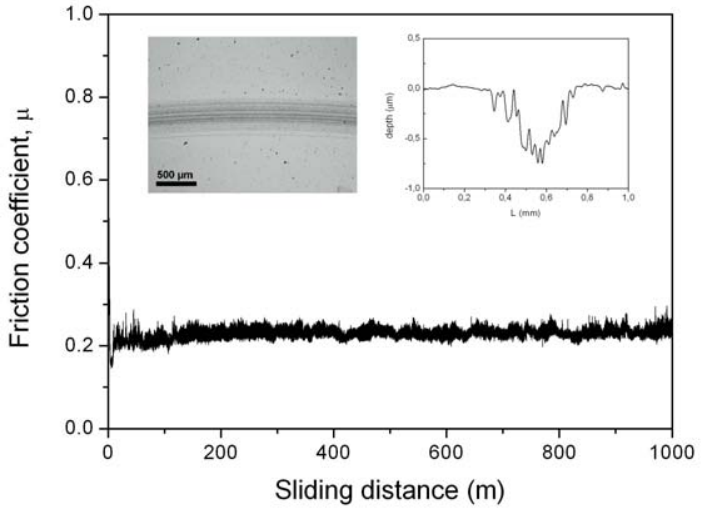




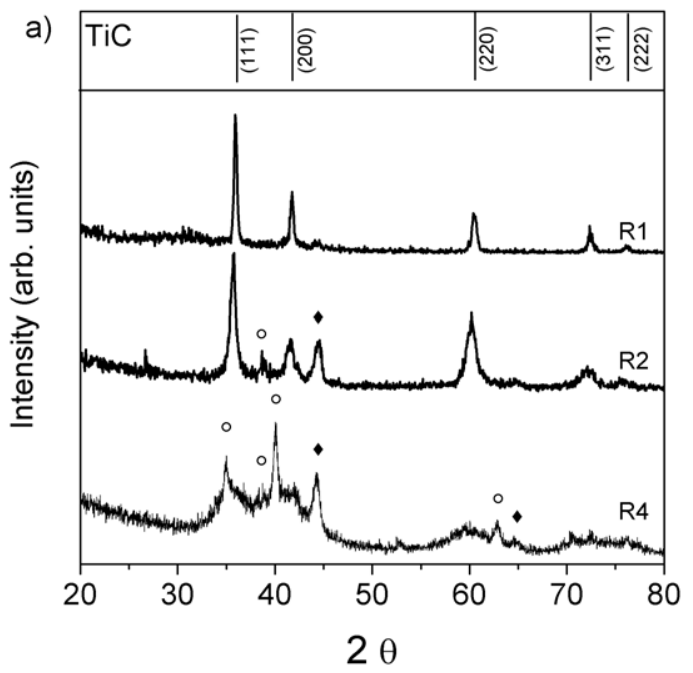




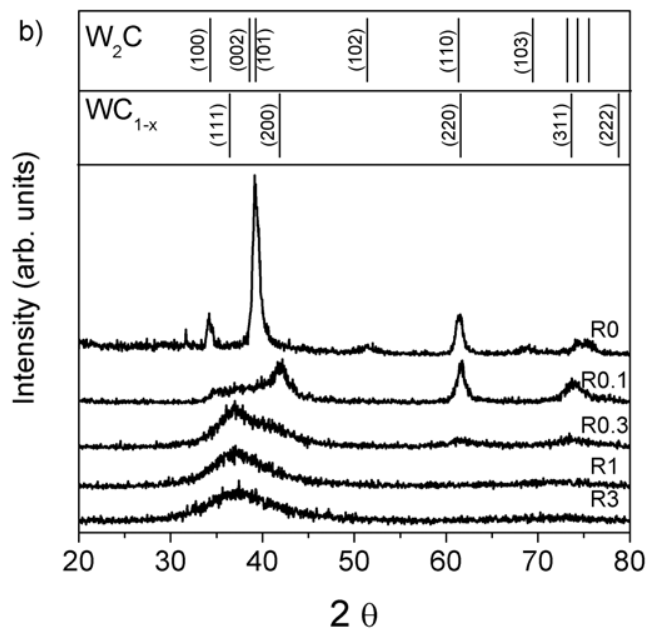




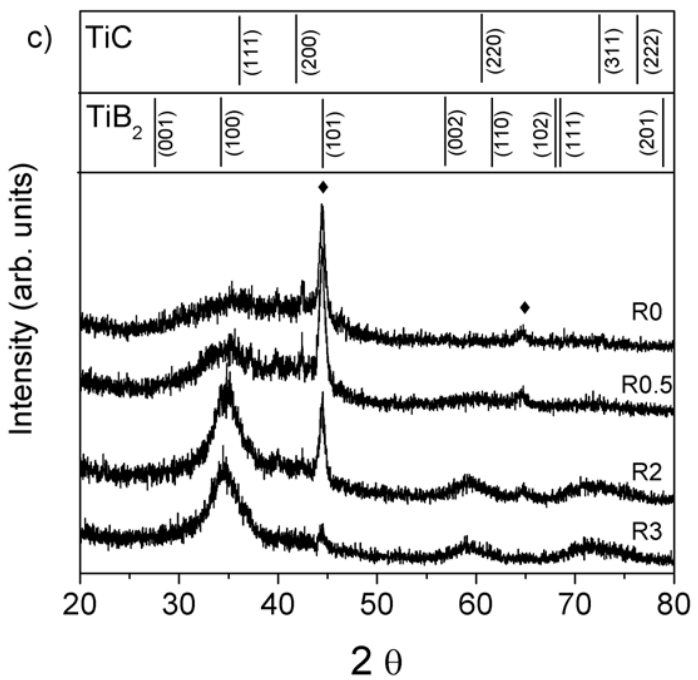




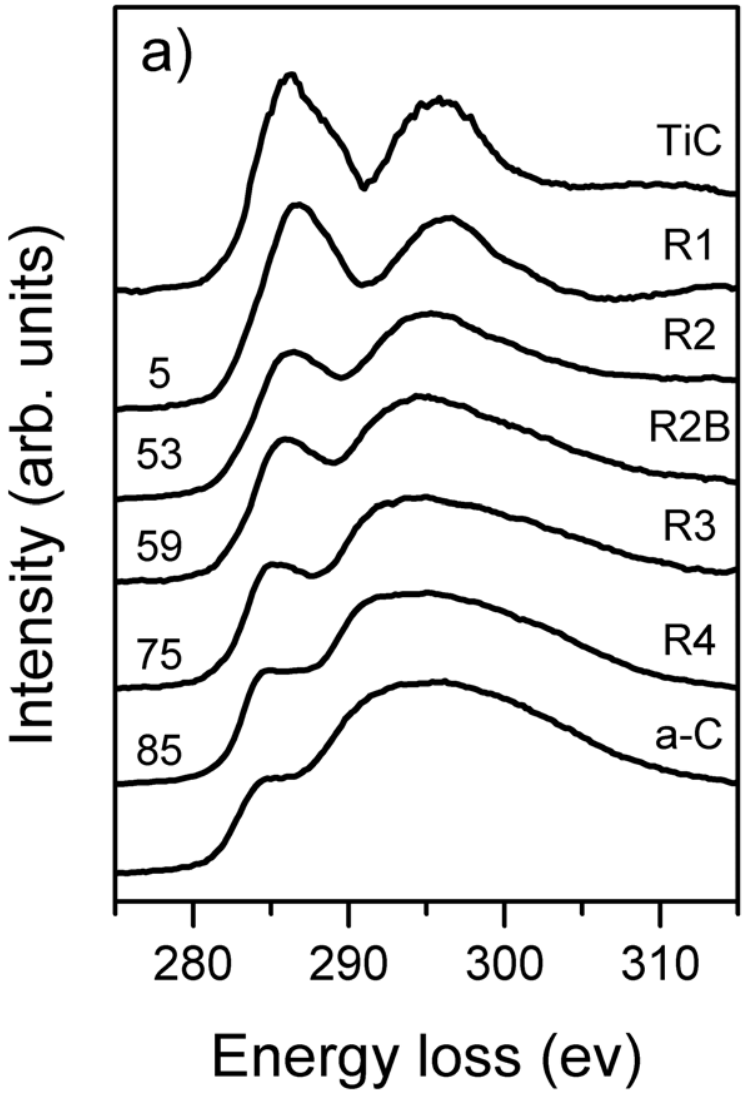




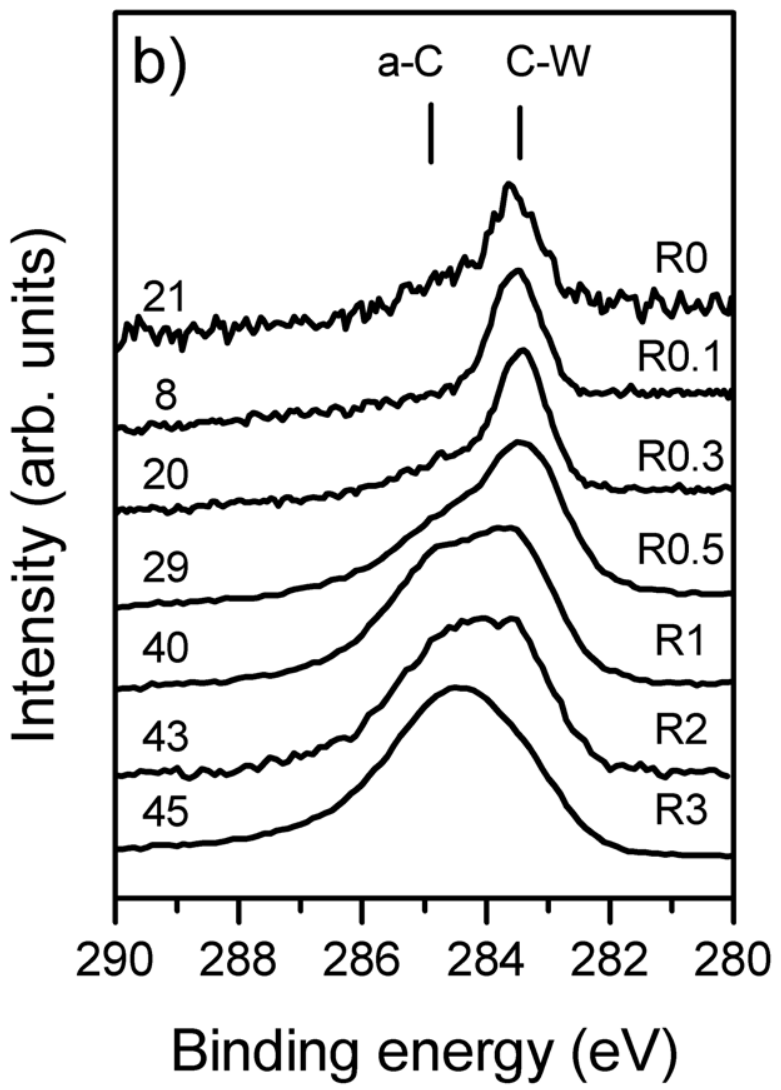




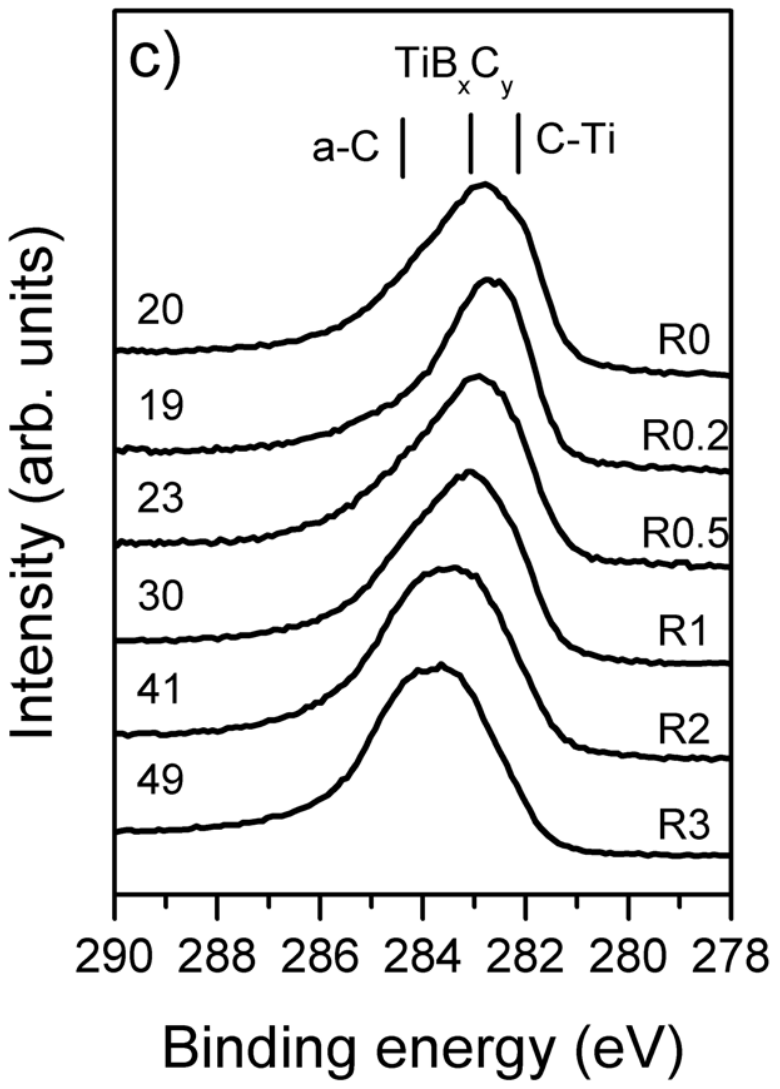




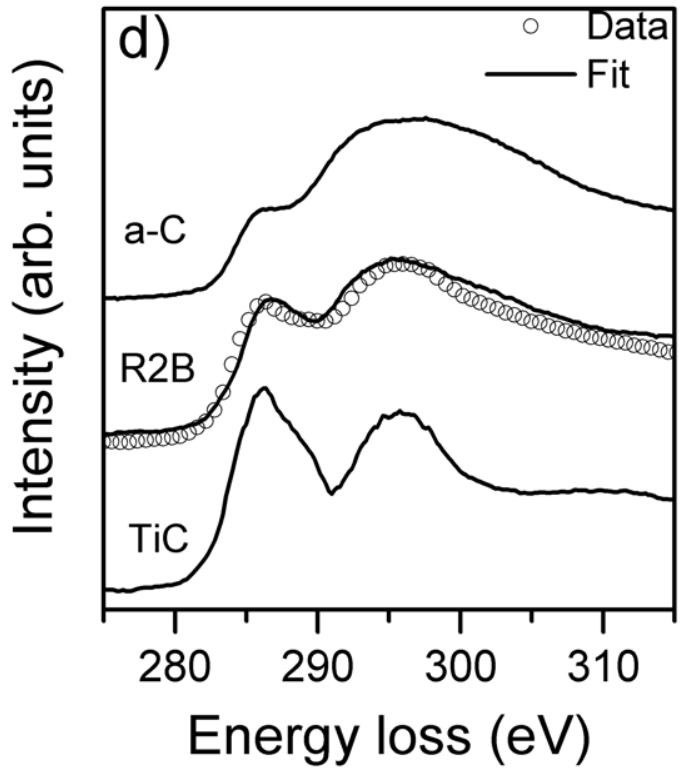




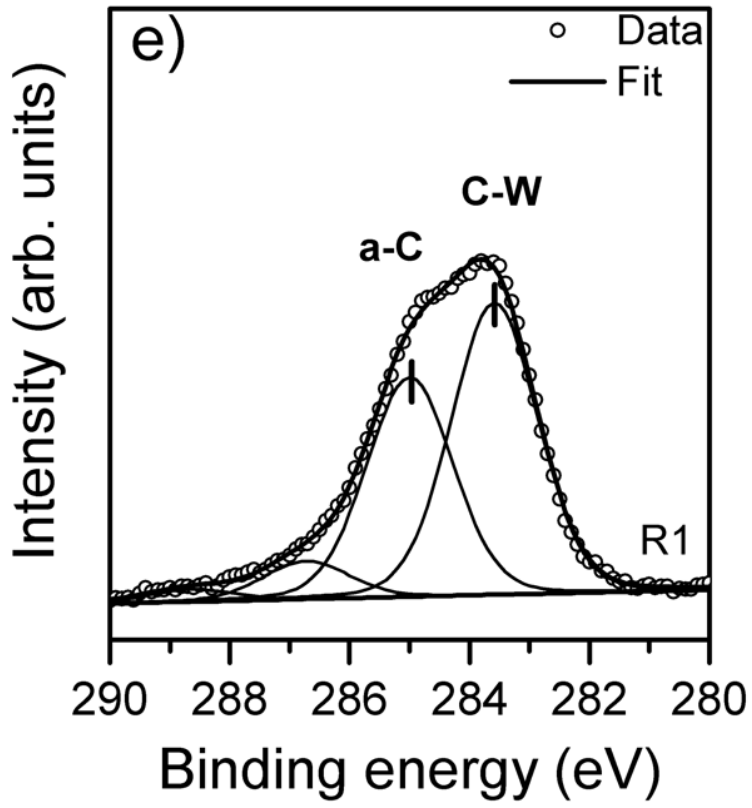




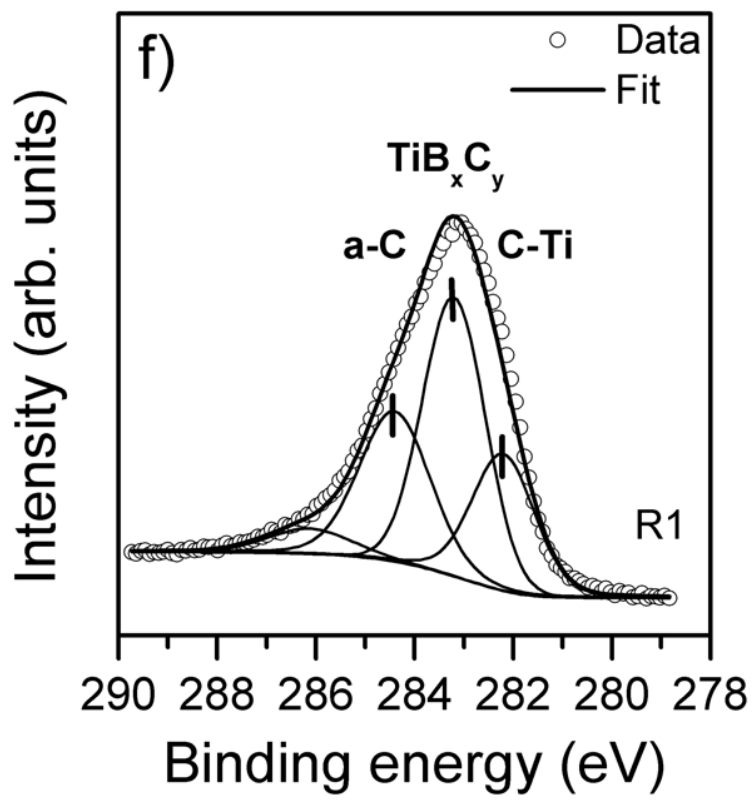




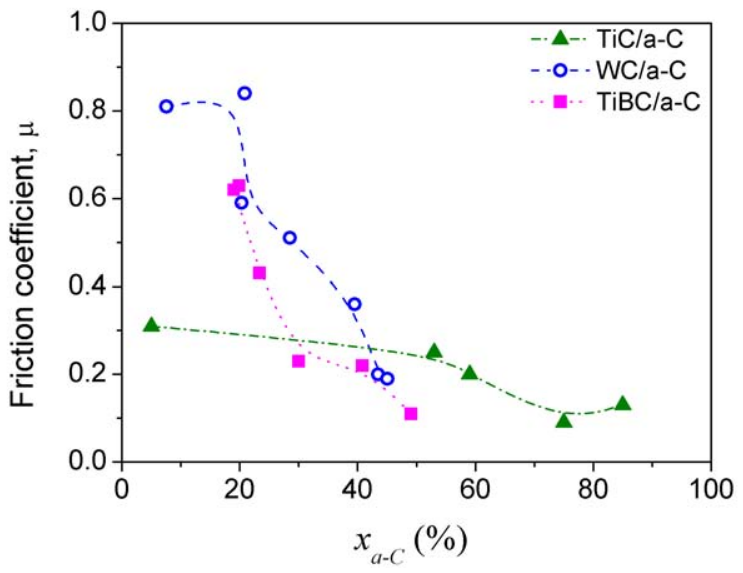




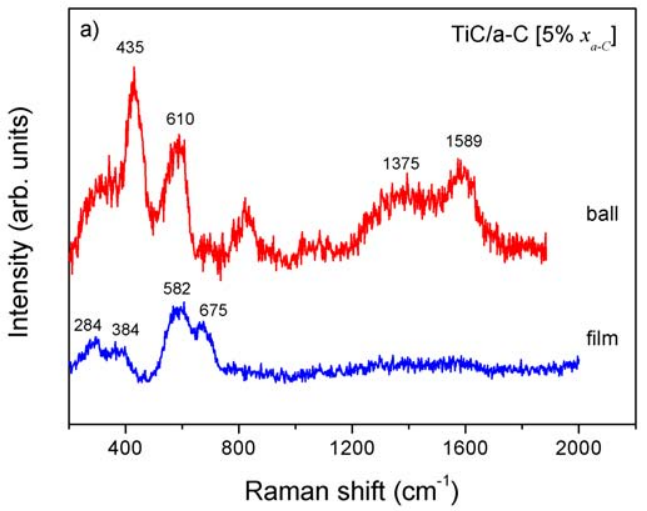




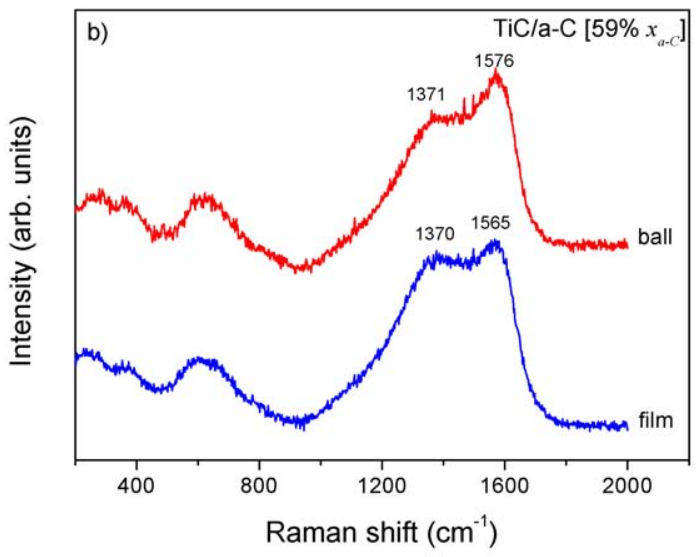




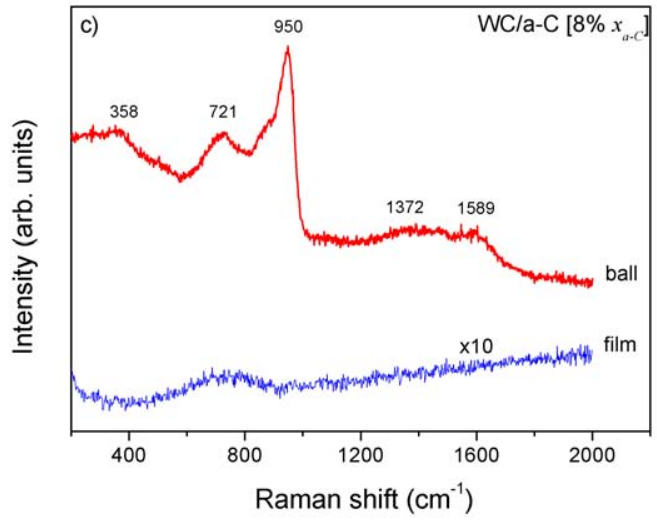




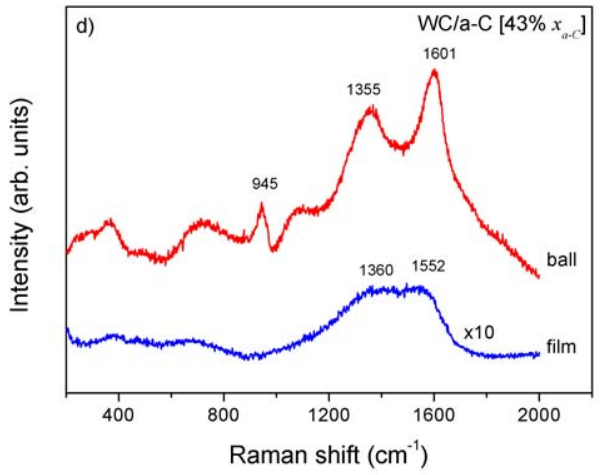




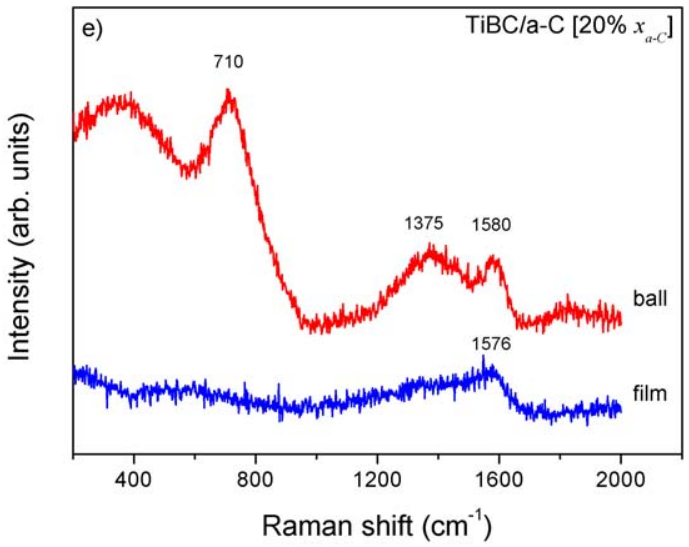




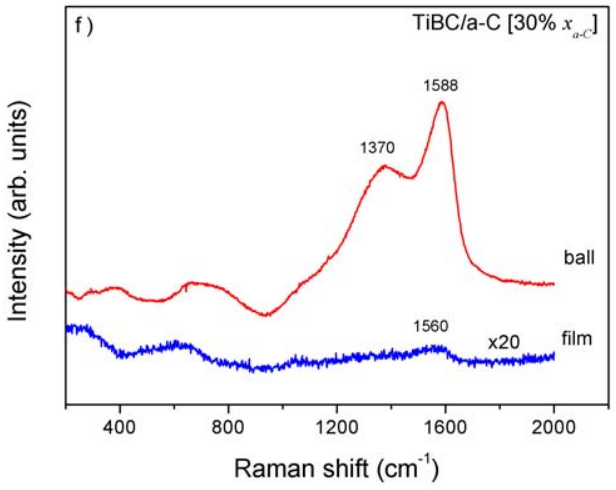

